\title{
Taxonomic revision of Garcinia section Garcinia (Clusiaceae)
}

\begin{abstract}
Species of Garcinia sect. Garcinia are typically understorey trees in rain forest and are distributed from eastern India to Malesia. A taxonomic revision of Garcinia section Garcinia (Clusiaceae) has resulted in the recognition of 13 species, two of which have three varieties each. Several species are excluded from Garcinia section Garcinia, reported as insufficiently known, or reduced to synonymy. Five species, G. acuticosta, G. discoidea, G. exigua, G. ochracea and G. sangudsangud, and two varieties, G. diospyrifolia var. minor and G. mangostana var. borneensis, are newly described. Morphological characters that are important for sectional delimitation are terminally attached inflorescences of simple cymes, stamen bundles 4 or 4-angled, and fruits with a smooth surface. Species limits are defined on the basis of a combination of characters of the male flower (i.e. shape of stamens, presence of pistillode), type of fruit, and characters of the leaf (shape and size, venation pattern and glandular lines).
\end{abstract}

Keyword: Garcinia; Clusiaceae; Asia; Eudicots 